\title{
UV Filtering of Dye-Sensitized Solar Cells: The Effects of Varying the UV Cut-Off upon Cell Performance and Incident Photon-to-Electron Conversion Efficiency
}

\author{
Matthew Carnie, Trystan Watson, and David Worsley \\ SPECIFIC, College of Engineering, Swansea University, Baglan Bay Innovation Centre, Central Avenue, Baglan Energy Park, \\ Baglan, Port Talbot SA12 7AZ, UK \\ Correspondence should be addressed to David Worsley, d.a.worsley@swansea.ac.uk
}

Received 22 December 2011; Accepted 6 February 2012

Academic Editor: Panagiotis Lianos

Copyright ( $) 2012$ Matthew Carnie et al. This is an open access article distributed under the Creative Commons Attribution License, which permits unrestricted use, distribution, and reproduction in any medium, provided the original work is properly cited.

With current technology, UV filters are essential to ensure long-term dye-sensitized solar cell (DSC) stability. Blocking photons, however, will have an obvious effect on device performance and upon its incident photon-to-current conversion efficiency (IPCE). Filters have been applied to DSC devices with a range of cut-off wavelengths in order to assess how different levels of filtering affect the performance and IPCE of devices made with three different dyes, namely N719, Z907, and N749. It is shown that dyes that extend their IPCE further into the NIR region suffer lesser relative efficiency losses due to UV filtering than dyes with narrower action spectra. Furthermore, the results are encouraging to those working towards the industrialisation of DSC technology. From the results presented it can be estimated that filtering at a level intended to prevent direct band gap excitation of the $\mathrm{TiO}_{2}$ semiconductor should cause a relative drop in cell efficiency of no more than $10 \%$ in forward illuminated devices and no more than $2 \%$ in reverse illuminated devices.

\section{Introduction}

One of the most important considerations for those working towards the commercialisation of dye-sensitized solar cells (DSCs) is their long-term stability. The importance has been recognised by many and some notable works have been published [1-9] as well as an extensive review of DSC stability published in 2010 [10]. Dye stability has historically been given particular consideration and was recognised as an important factor in O'Regan's and Grätzel breakthrough paper of 1991 [11]. The dye was perhaps once considered to be a weak link in the device but there is now considerable evidence that robust dyes have been developed [12-14] and that they can survive over 100 million redox turnovers to achieve a 20-year lifetime [15]. However, dye stability still remains a concern to DSC researchers [10].

In recent years it has been observed that the $\mathrm{I}_{3}^{-} / \mathrm{I}^{-}$redox couple is susceptible to photodegradation and in particular a depletion of the $\mathrm{I}_{3}^{-}$has been noted. This has been observed in DSCs subjected to outdoor testing and is evidenced by an increase in the Nernst diffusion impedance and changes to the cell Raman spectra [5]. In accelerated tests at $85^{\circ} \mathrm{C}$, it was shown that loss of $\mathrm{I}_{3}^{-}$was only observed in illuminated cells and not in cells kept at $85^{\circ} \mathrm{C}$ in the dark [2]. Mechanisms for the observed $\mathrm{I}_{3}^{-}$losses have been proposed as either the sublimination of iodine [7] or perhaps the formation of iodate by reactions with water or other impurities in the electrolyte [16]. Whatever the mechanism, loss of $I_{3}^{-}$ will have an obvious effect on cell performance and indeed it has been shown that depletion of $\mathrm{I}_{3}^{-}$in extreme cases causes a reduction in $J_{\mathrm{SC}}$ by diffusion limitation [17]. Other studies have shown that UV exposure plays a critical role in degradation of the electrolyte as DSC modules can degrade quickly under UV illumination [18]. This coupled with the fact that filtering at $\lambda<384 \mathrm{~nm}$ improves the stability of a DSC cell [19] suggests that the degradation may be as a result of a photocatalytic reaction caused by direct excitation of the $\mathrm{TiO}_{2}$ band gap. 
It has been suggested that in DSCs, the photogenerated hole in the $\mathrm{TiO}_{2}$ valence band may be quenched by the iodide ion in the electrolyte [1]. However, recently we reported that UV-exposed cells degrade more quickly and show an increased rate of $\mathrm{I}_{3}^{-}$consumption when exposed under an electrical load than cells exposed under open circuit conditions. We have hypothesised that under load there is an increased concentration of photogenerated holes due to exportation of electrons in the $\mathrm{TiO}_{2}$ conduction band to the external circuit, leading to an increased rate of photodegradation [20].

In order to prevent direct band gap excitation of $\mathrm{TiO}_{2}$, the simplest solution would be to use a UV cut-off filter and indeed there are reports where UV cut-off filters have been employed in stability testing $[19,21,22]$. The question this leaves therefore is: How much filtering is required and to what extent does this affect cell efficiency?

The band gaps of rutile $(3.02 \mathrm{eV})$ and anatase $(3.2 \mathrm{eV})$ mean that the most common crystalline forms of $\mathrm{TiO}_{2}$ are photoactive up to $387 \mathrm{~nm}$ (anatase) and $411 \mathrm{~nm}$ (rutile). The anatase-to-rutile phase transition is immeasurably slow below $610^{\circ} \mathrm{C}$ [23] meaning that $\mathrm{TiO}_{2}$ films made with pure anatase and sintered below $610^{\circ} \mathrm{C}$ should remain pure anatase and therefore a cut-off filter that blocks light below $390 \mathrm{~nm}$ should suffice. Our recent work using cells made with Dyesol 18NR-T paste, which is made with pure anatase, suggests that a filter with a $385 \mathrm{~nm}$ cut-off slows photodegradation considerably but was not sufficient to prevent photodegradation completely. We also found that there was no extra benefit gained from filtering above $400 \mathrm{~nm}$ [20]. If the $\mathrm{TiO}_{2}$ starting material is a mixture of anatase and rutile, such as Degussa P25, then filtering may be required up to $411 \mathrm{~nm}$. It should be noted, however, that in general rutile is considered to be less photoactive than anatase due to a higher rate of electron-hole recombination that is attributed to rutile lower capacity to adsorb oxygen onto its surface [24]. The purpose of this paper, however, is not to determine the level of filtering required but to consider different levels of filtering and to determine how this might affect cell performance. When looking at IPCEs, test cells made with the best performing dyes generate photocurrent down to around $300 \mathrm{~nm}$, and so, by using a cut-off filter, photons that could otherwise be converted into current are being blocked. This perhaps reinforces the need to widen the spectral response of the cell into the near infrared region, something that has been recognised since before the development of the black dye, N749, in 2001 [25]. In order to investigate how the spectral response of the cell might affect the efficiency losses due to filtering, three dyes were chosen: N719, N749the "black dye" which has a broader spectral response than N719, and Z907, a hydrophobic dye which has a narrower spectral response than N719.

\section{Experimental}

2.1. Cell Preparation. The photoanode was prepared by the doctor blading of a commercial $\mathrm{TiO}_{2}$ paste (DSL 18NRT (Dyesol)) onto Solaronix TCO22-15 fluorine doped $\mathrm{SnO}_{2}$

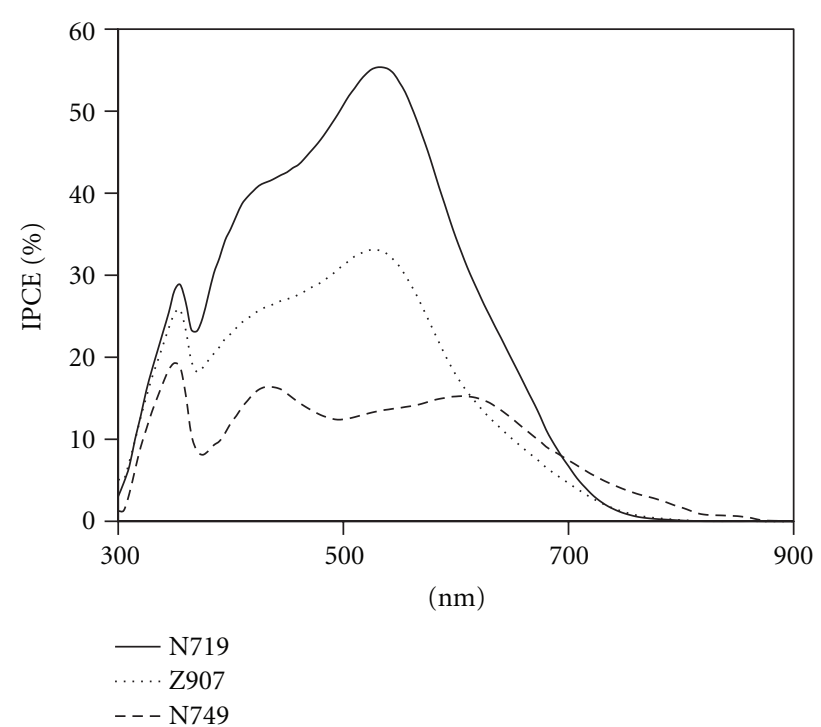

FIGURE 1: Comparison of typical IPCE spectra for the three different dyes.

glass followed by sintering at $500^{\circ} \mathrm{C}$ for 30 minutes giving a $7 \mu \mathrm{m}$ dry film thickness. The counterelectrodes were prepared by the deposition of $5 \mathrm{mM}$ chloroplatinic acid and heat treated at $400^{\circ} \mathrm{C}$ for 30 minutes. The dyes were prepared at $0.3 \mathrm{mM}$ in a $1: 1$ acetonitrile/T-butanol solution. Adsorption of the dye to the $\mathrm{TiO}_{2}$ was achieved by immersion of the electrode in the dye solution over a period of 1620 hours. $50 \mu \mathrm{m}$ Surlyn gaskets were used to separate the electrodes, and an electrolyte solution (0.8 M 1-propyl-3methylimidazolium iodide (PMII), 0.3 M benzimidazole, $0.1 \mathrm{M} \mathrm{I}_{2}$ and $0.05 \mathrm{M}$ guanidinium thiocyanate dissolved in $\mathrm{N}$-methoxy propionitrile) was then introduced to the cell by vacuum injection. All test cells were made with a working electrode area of $1 \mathrm{~cm}^{2}$.

2.2. Measurements. Photovoltaic characterisation was carried out using an Oriel Sol3A (94023A) solar simulator, utilizing a xenon arc lamp, an AM 1.5 filter, and a Keithley 2400 source meter. A reference measurement was provided using a monocrystalline silicon reference cell traceable to the National Renewable Energy Laboratory (NREL) that enabled adjustment of the solar simulator to the standard light intensity of one sun, that is, $100 \mathrm{~mW} / \mathrm{cm}^{2}$. IPCE measurements were carried out using a Dyesol IPCE measurement apparatus. UV-Vis spectra were obtained with a Perkin Elmer Lameda 750 s UV-Vis-NIR spectrophotometer.

\section{Results and Discussion}

3.1. Dyes. The dyes were chosen due to their differing IPCE characteristics. N749 has the broadest action spectrum, N719 has the median action spectrum, and Z907 has the narrowest action spectrum even though its IPCE extends out to $780 \mathrm{~nm}$ (the same as for N719). Typical IPCEs for the cells are shown in Figure 1. It is apparent that cells manufactured 
TABLE 1: Mean properties for cells made with the dyes shown.

\begin{tabular}{|c|c|c|c|c|c|}
\hline & $V_{\mathrm{OC}}(\mathrm{V})$ & $J_{\mathrm{SC}}\left(\mathrm{mAcm}^{-2}\right)$ & $P_{\max }(\mathrm{mW})$ & Fill Factor & $\% \eta$ \\
\hline N719 & $0.731( \pm 0.005)$ & $7.15( \pm 0.09)$ & $3.62( \pm 0.02)$ & $0.77( \pm 0.02)$ & $4.0( \pm 0.02)$ \\
\hline Z907 & $0.682( \pm 0.007)$ & $4.21( \pm 0.15)$ & $1.89( \pm 0.09)$ & $0.73( \pm 0.02)$ & $2.1( \pm 0.10)$ \\
\hline N749 & $0.685( \pm 0.016)$ & $3.83( \pm 0.31)$ & $1.74( \pm 0.08)$ & $0.74( \pm 0.01)$ & $1.9( \pm 0.09)$ \\
\hline
\end{tabular}

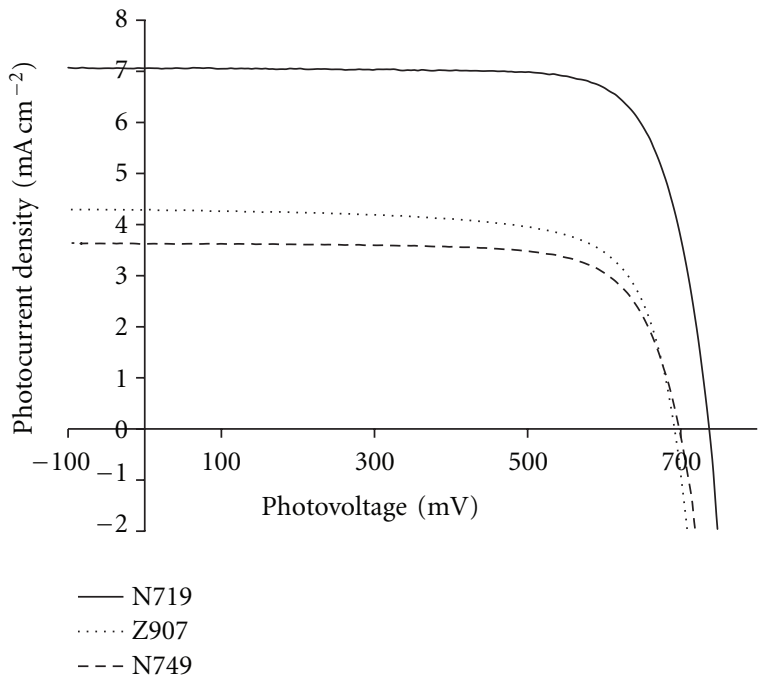

Figure 2: Comparison of typical $I-V$ curves for the three different dyes.

with N749 and Z907 dyes show reduced quantum efficiencies when compared to cells made with N719. This may be because our method of manufacture is optimised for N719 cells. It was important, however, to maintain the same method of manufacture for each cell type, especially the electrolyte composition as reverse illumination through the counterelectrode (and hence through the electrolyte) is being considered in this work, it was important that the electrolyte formulation remained the same for all cells. The difference in performance can also be seen in $I-V$ curves (Figure 2). The important mean cell properties can also be seen in Table 1 . Despite the lower relative performance of Z907 and N749 cells, we believe the results presented in the following sections show how important the spectral response of a device is with regards to how it is affected by UV filtering.

3.2. Filters. The filters used were polymeric (PET) with differing cut-off wavelengths. Their optical properties are summarised in Table 2, and their UV-Vis transmission curves are shown in Figure 3. The filters are designated as $\lambda_{320}, \lambda_{385}, \lambda_{420}$, and $\lambda_{480}$ with the subscript number referring to the wavelength at which their \% transmittance is at $50 \%$ of its maximum value. $\lambda_{320}$ is PET (Melinex ST505 from DuPont), and $\lambda_{385}$ is the same film but coated with a highperformance UV absorbing lacquer. $\lambda_{420}$ is an experimental film based on PET and obtained via Tata Steel Colours. $\lambda_{480}$ is a PET filter (Lee Filters Spring Yellow) coated with highperformance lacquer to remove some UV transmittance at around $340 \mathrm{~nm}$. It is highly unlikely and undesirable that
TABLE 2: Optical properties of polymer filters.

\begin{tabular}{lccc}
\hline Filter name & $\begin{array}{c}\text { Mean \%T } \\
(500 \mathrm{~nm}-800 \mathrm{~nm})\end{array}$ & $\begin{array}{c}\lambda \text { at 50\% max } \\
\text { transmittance }\end{array}$ & $\begin{array}{c}\lambda \text { at } \\
\% T<1\end{array}$ \\
\hline$\lambda_{320}$ & $88.2 \%$ & $320 \mathrm{~nm}$ & $305 \mathrm{~nm}$ \\
$\lambda_{385}$ & $90.2 \%$ & $385 \mathrm{~nm}$ & $320 \mathrm{~nm}$ \\
$\lambda_{420}$ & $87.4 \%$ & $420 \mathrm{~nm}$ & $405 \mathrm{~nm}$ \\
$\lambda_{480}$ & $87.2 \%$ & $480 \mathrm{~nm}$ & $465 \mathrm{~nm}$ \\
\hline
\end{tabular}

DSC modules be filtered to the extent that $\lambda_{480}$ provides but $\lambda_{480}$ has still been included to show how extreme filtering may affect DSC performance. It is interesting to note that $\lambda_{385}$ has a higher mean \% transmittance than $\lambda_{320}$ in the region from $500 \mathrm{~nm}$ to $800 \mathrm{~nm}$ even though they are essential the same film, the only difference being that $\lambda_{385}$ is the $\lambda_{320}$ filter coated with a UV absorbing polyurethane (PU) clear lacquer. It is thought that this increased transmittance is caused by antireflection and is due to the difference in the refractive indices of the PU lacquer and PET substrate.

3.3. The Effects of Filtering upon the IPCE of Forward Illuminated Cells. Figures 4(a), 4(b) and 4(c) show the effect of filtering upon the IPCEs of the three cell types. In all cases where a filter is applied the overall IPCE is reduced due to a loss of light transmission through the polymer films. All the filters except $\lambda_{320}$ significantly alter the shape of the IPCE spectra by blocking photons in the UV and blue spectral regions. Although these results are to be expected and easily predictable, showing them in this way emphasises how even filtering at $385 \mathrm{~nm}$, which has been shown to slow photodegradation of DSC devices $[19,20,26]$, can have a significant effect on IPCE shape and therefore cell performance.

3.4. The Effects of Filtering upon the I-V Characteristics of Forward Illuminated Cells. The cell sets were all measured using the solar simulator and their main $I-V$ properties are summarised in Table 3. The NREL traceable silicon reference cell used to calibrate the solar simulator lamp was also used to measure the intensity of light transmitted through the filter simply by placing the filters over the reference cell and illuminating at 1 sun $\left(100 \mathrm{~mW} \mathrm{~cm}^{-2}\right)$. The incident light falling upon the cell, $I_{0}$ is plotted against the measured $J_{\mathrm{SC}}$ and $V_{\mathrm{OC}}$ in Figure 5. As one would expect, the reduction in $J_{\mathrm{SC}}$ is directly proportional to the reduction in incident photon flux, and due to the relationship described by Hagfeldt and Peter [27], the energy of $\mathrm{TiO}_{2}$ conduction band, and therefore $V_{\mathrm{OC}}$, is also proportional to $I_{0}$. 
TABLE 3: Summary of $I-V$ data for filtered and unfiltered, forward illuminated cells.

\begin{tabular}{|c|c|c|c|c|c|}
\hline Dye-filter & $V_{\mathrm{OC}}(\mathrm{V})$ & $J_{\mathrm{SC}}\left(\mathrm{mA} \mathrm{cm}^{-2}\right)$ & $P_{\max }(\mathrm{mW})$ & Fill factor & $\% \eta$ \\
\hline N719-unfiltered & $0.731( \pm 0.006)$ & $7.15( \pm 0.09)$ & $3.62( \pm 0.02)$ & $0.77( \pm 0.007)$ & $4.01( \pm 0.02)$ \\
\hline N719- $\lambda_{320}$ & $0.718( \pm 0.006)$ & $6.33( \pm 0.09)$ & $3.16( \pm 0.01)$ & $0.77( \pm 0.004)$ & $3.50( \pm 0.01)$ \\
\hline N719- $\lambda_{385}$ & $0.720( \pm 0.004)$ & $6.27( \pm 0.05)$ & $3.14( \pm 0.01)$ & $0.77( \pm 0.009)$ & $3.47( \pm 0.01)$ \\
\hline N719- $\lambda_{420}$ & $0.709( \pm 0.007)$ & $5.66( \pm 0.08)$ & $2.79( \pm 0.01)$ & $0.77( \pm 0.004)$ & $3.09( \pm 0.01)$ \\
\hline N719- $\lambda_{480}$ & $0.698( \pm 0.008)$ & $4.35( \pm 0.06)$ & $2.11( \pm 0.01)$ & $0.77( \pm 0.003)$ & $2.34( \pm 0.01)$ \\
\hline Dye-filter & $V_{\mathrm{OC}}(\mathrm{V})$ & $J_{\mathrm{SC}}\left(\mathrm{mA} \mathrm{cm}^{-2}\right)$ & $P_{\max }(\mathrm{mW})$ & Fill factor & $\% \eta$ \\
\hline Z907-unfiltered & $0.682( \pm 0.007)$ & $4.21( \pm 0.15)$ & $1.89( \pm 0.09)$ & $0.73( \pm 0.018)$ & $2.09( \pm 0.09)$ \\
\hline$Z 907-\lambda_{320}$ & $0.668( \pm 0.006)$ & $3.68( \pm 0.13)$ & $1.60( \pm 0.08)$ & $0.72( \pm 0.018)$ & $1.78( \pm 0.09)$ \\
\hline$Z 907-\lambda_{385}$ & $0.665( \pm 0.007)$ & $3.62( \pm 0.14)$ & $1.57( \pm 0.09)$ & $0.72( \pm 0.019)$ & $1.74( \pm 0.09)$ \\
\hline$Z 907-\lambda_{420}$ & $0.658( \pm 0.008)$ & $3.21( \pm 0.13)$ & $1.38( \pm 0.08)$ & $0.72( \pm 0.018)$ & $1.53( \pm 0.09)$ \\
\hline$Z 907-\lambda_{480}$ & $0.647( \pm 0.007)$ & $2.41( \pm 0.10)$ & $1.01( \pm 0.06)$ & $0.72( \pm 0.019)$ & $1.12( \pm 0.09)$ \\
\hline Dye-filter & $V_{\mathrm{OC}}(\mathrm{V})$ & $J_{\mathrm{SC}}\left(\mathrm{mA} \mathrm{cm}^{-2}\right)$ & $P_{\max }(\mathrm{mW})$ & Fill factor & $\% \eta$ \\
\hline N749-unfiltered & $0.685( \pm 0.016)$ & $3.83( \pm 0.31)$ & $1.74( \pm 0.09)$ & $0.74( \pm 0.006)$ & $1.93( \pm 0.10)$ \\
\hline N749- $\lambda_{320}$ & $0.669( \pm 0.016)$ & $3.41( \pm 0.29)$ & $1.51( \pm 0.09)$ & $0.74( \pm 0.005)$ & $1.68( \pm 0.10)$ \\
\hline N749- $\lambda_{385}$ & $0.674( \pm 0.016)$ & $3.45( \pm 0.33)$ & $1.54( \pm 0.11)$ & $0.74( \pm 0.04)$ & $1.71( \pm 0.13)$ \\
\hline N749- $\lambda_{420}$ & $0.664( \pm 0.016)$ & $3.13( \pm 0.30)$ & $1.38( \pm 0.01)$ & $0.74( \pm 0.005)$ & $1.53( \pm 0.11)$ \\
\hline N749- $\lambda_{480}$ & $0.655( \pm 0.016)$ & $2.51( \pm 0.24)$ & $1.09( \pm 0.08)$ & $0.74( \pm 0.004)$ & $1.21( \pm 0.09)$ \\
\hline
\end{tabular}

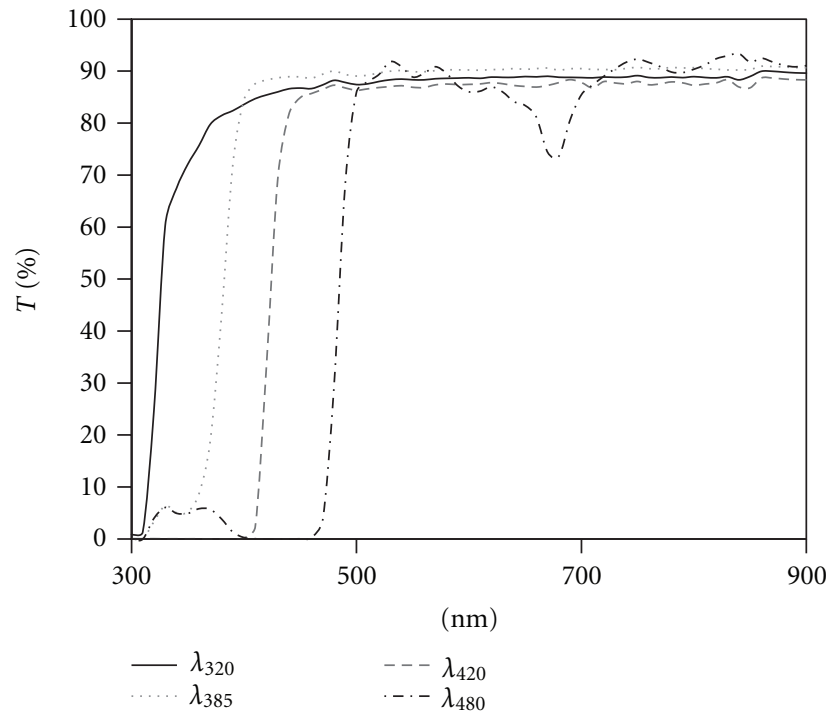

Figure 3: UV-Vis \%T curves of PET-based UV cut-off filters.

Looking at the IPCE and UV-Vis data presented so far it appears that reduction in $\% \eta$ caused by the $\lambda_{320}$ filter is mainly due to the overall transmission losses rather than the cut-off at $320 \mathrm{~nm}$. The $\lambda_{320}$ filter is an unmodified sheet of PET, and it is likely, especially in flexible devices, that a PET film may be intrinsic to that device. For these two reasons it is perhaps more useful to compare the drop in efficiency caused by increasing UV cut-off to devices measured with the $\lambda_{320}$ filter rather than to devices measured with no filter. Figure 6 is a bar chart that shows the relative efficiency losses in filtered cells compared to the efficiency of cells measured with the $\lambda_{320}$ filter. Looking at Figure 6 it is clear that those devices made with dyes whose activity extends further toward the NIR region suffer lesser efficiency losses than those with narrower action spectra. Efficiency losses are greatest in devices made with Z907 dye and least in those made with the N749 dye. It is interesting to note that in N749 devices the $\% \eta$ is greater in cells filtered with $\lambda_{320}$ than it is in cells filtered with $\lambda_{385}$. Looking at Table 3 , it conceivable that this is caused by experimental error but the fact that $\lambda_{385}$ has a higher average light transmission than $\lambda_{320}$ suggests that this may be an aspect of the antireflection that is a result of the difference in the refractive indices of the PET substrate and the PU lacquer. This then leads to the question: Why does this increase in $\% \eta$ only manifest itself in cells made with N749 dye and not with the cells made with the other dyes? The answer could be that as the UV cut-off of the filter becomes less important with the broadening spectrum of the dye then other factors, such as a small increase in transmitted light through the filter, may have an effect. A slight increase in light transmission would obviously cause a slight increase in cell efficiency. This is not observed in cells made with other dyes as the decrease in efficiency due to the UV cutoff far outweighs any antireflection benefits caused by the PU lacquer.

For those working towards the industrialisation of DSC technology, the results presented in Figure 6 are encouraging as filtering at $385 \mathrm{~nm}$, which has been shown to significantly impede photodegradation, causes only a small drop in efficiency. Furthermore, if a UV filter with a $385 \mathrm{~nm}$ UV cutoff is incorporated into a flexible metal-based DSC, then, when combined with a broad action dye and antireflection technology, the UV filter need not cause any drop in cell efficiency at all. In fact it can be seen in Figure 6 that in some cases there might even be an improvement in cell efficiency (as seen by the negative value in Figure 6), which arises 


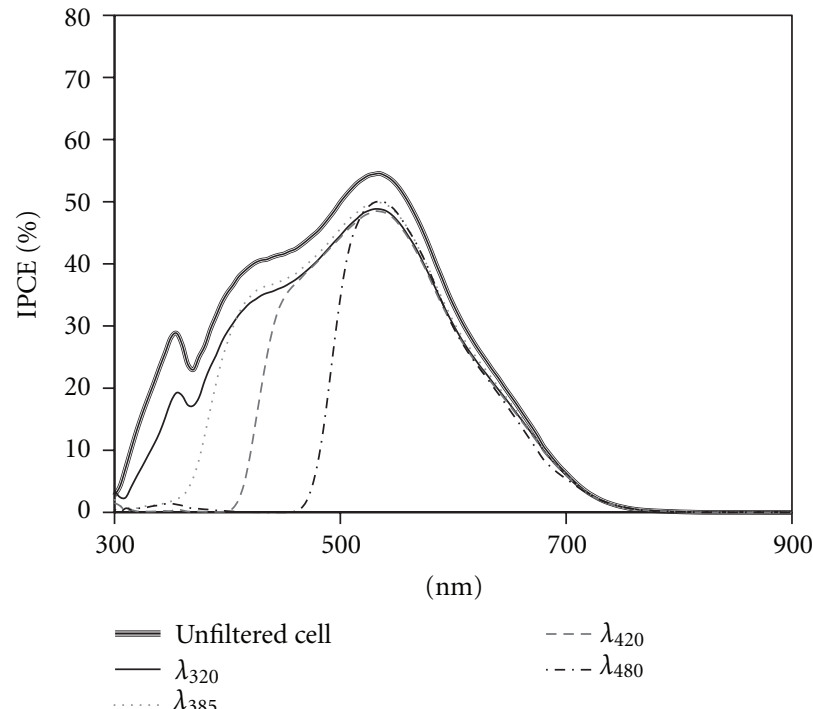

(a)

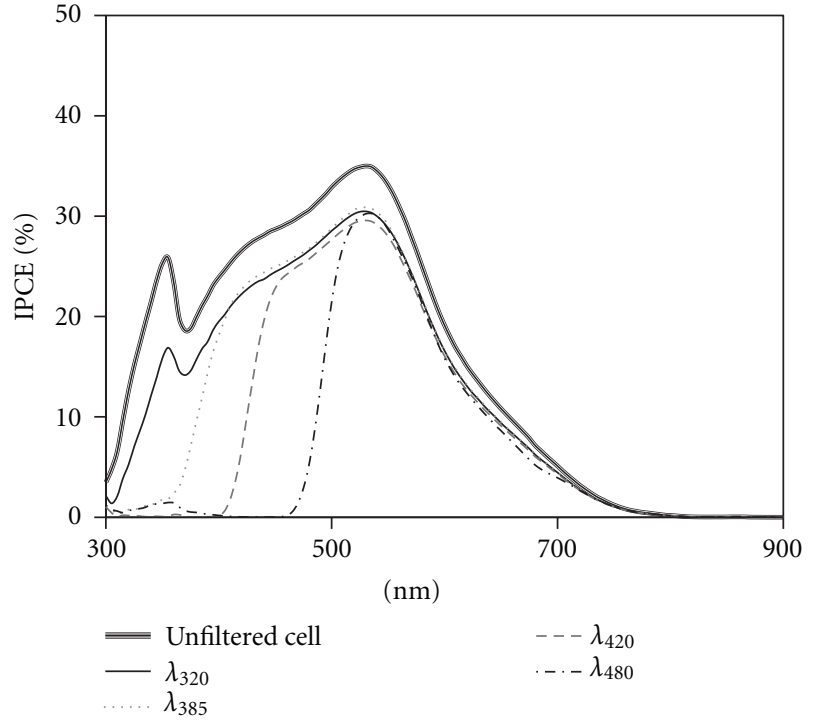

(b)

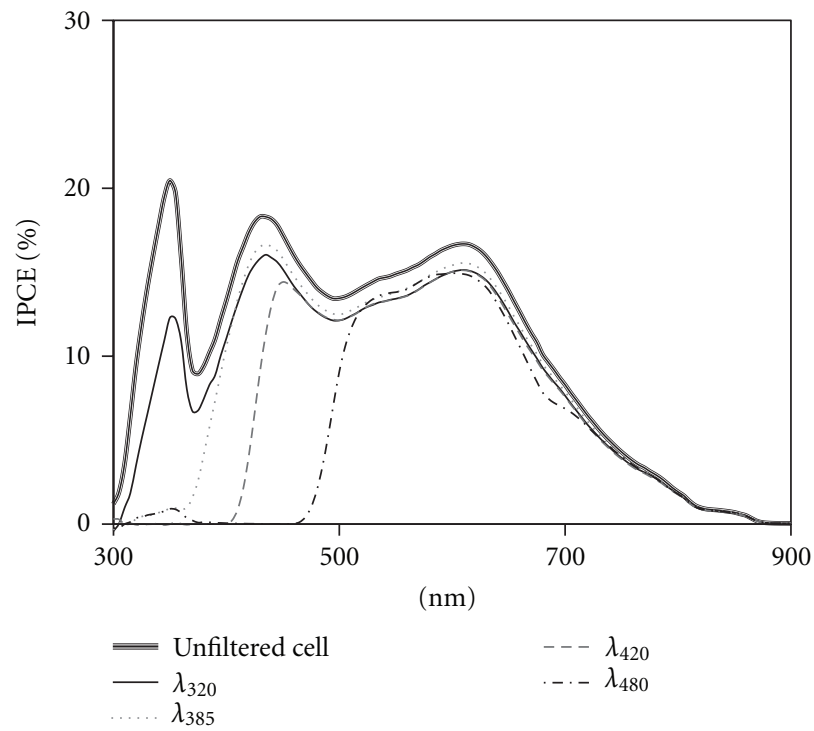

(c)

FIgUre 4: The effects of filtering upon the IPCEs of DSCs made with three different dyes: (a) N719, (b) Z907, and (c) N749.

from antireflection and is as a result of the difference in the refractive indices of the PET substrate and the UV absorbing PU topcoat.

If it arises that filtering of DSCs is required such that direct band gap excitation of $\mathrm{TiO}_{2}$ (anatase) is to be avoided completely, then it could be estimated, given that the $\% T$ of $\lambda_{420}$ is less than $1 \%$ at $405 \mathrm{~nm}$, that filtering at this level might cause a relative drop in $\% \eta$ of around $10 \%$ for cells made with N719 dye and less so for cells made with dyes with broader IPCE spectra. Thus, if modules were manufactured with efficiencies equal to the current efficiency record of $12.3 \%$ [28], then even the most extreme level of filtering might only reduce the efficiency to around $11.1 \%$.
3.5. The Effects of Filtering on Reverse Illuminated Cells. As this work was in part sponsored by Tata Steel who are developing DSC modules based upon a steel substrate and as this would require reverse illumination (i.e., through the counterelectrode and electrolyte) it was of interest to determine what might be the effects of filtering upon reverse illuminated cells. The triiodide redox mediator absorbs strongly in the UV and blue region of the spectrum and so reverse illuminated cells have lower efficiencies due to the electrolyte filtering out current-convertible photons. Figure 7 shows the IPCE spectra of a cell, made with N719 dye and measured in both forward and reverse illumination. Figure 7 also shows the UV-Vis $\% T$ curve of a model cell consisting of a platinised counter electrode (TCO glass), 


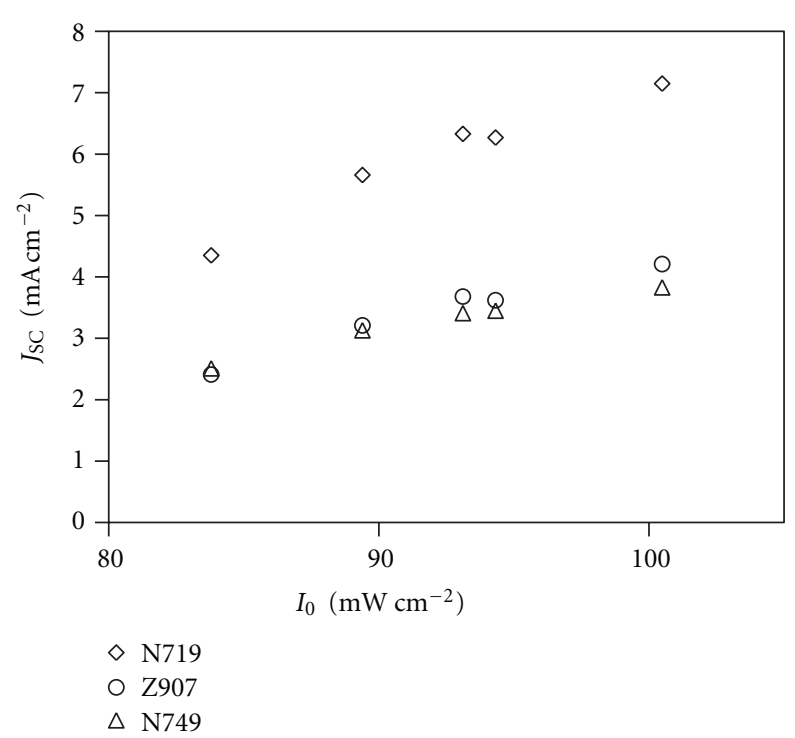

(a)

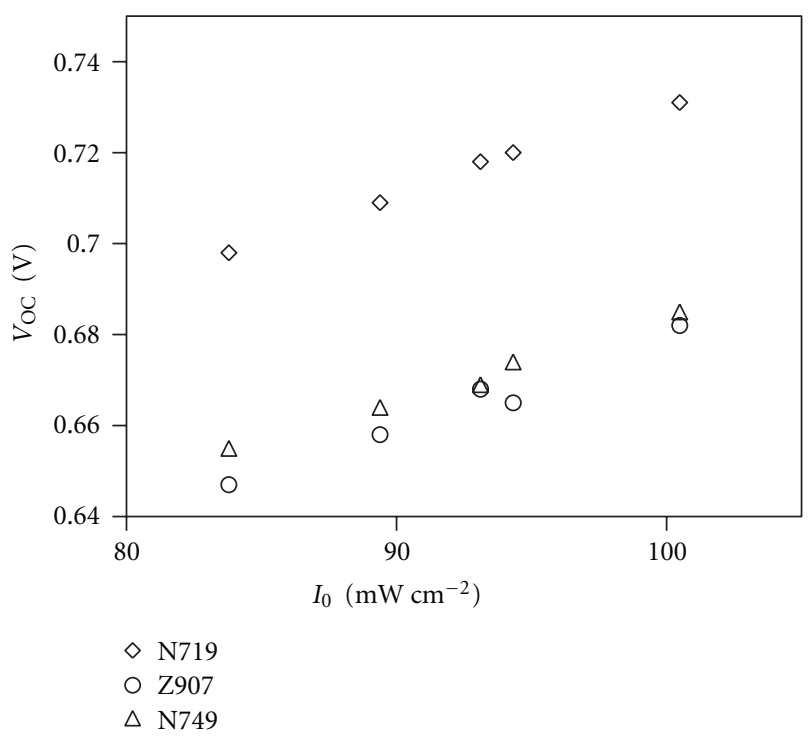

(b)

Figure 5: Reduction to (a) $J_{\mathrm{SC}}$ and (b) $V_{\mathrm{OC}}$ as a result of filtering reducing incident photon flux.

the electrolyte and ordinary soda-lime glass in place of the working electrode. The model cell simulates the filtering caused by the counter electrode and electrolyte when a DSC device is operated in reverse illumination. Therefore, the $\% T$ curve of this model cell gives an indication of the spectrum and intensity of light that is incident upon a photoanode in reverse illumination. Figure 7 shows how spectral filtering by the CE/electrolyte affects the IPCE spectrum of the cell. The effects of filtering are analogous to that which is caused by the devices measured under forward illumination and filtered using the polymer filters described in Section 3.2.

Figures 8(a), 8(b), and 8(c) show how the filters affect the IPCE spectra of the same cells used in Section 3.3 but under reverse illumination. Unlike the cells when measured

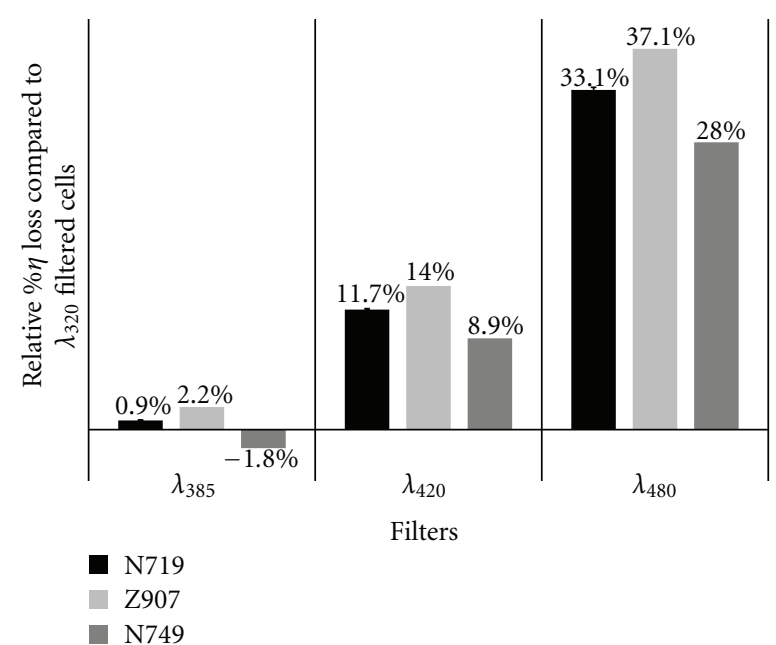

FIGURE 6: Efficiency losses caused by the filters shown compared to cells filtered with the $\lambda_{320}$ filter.

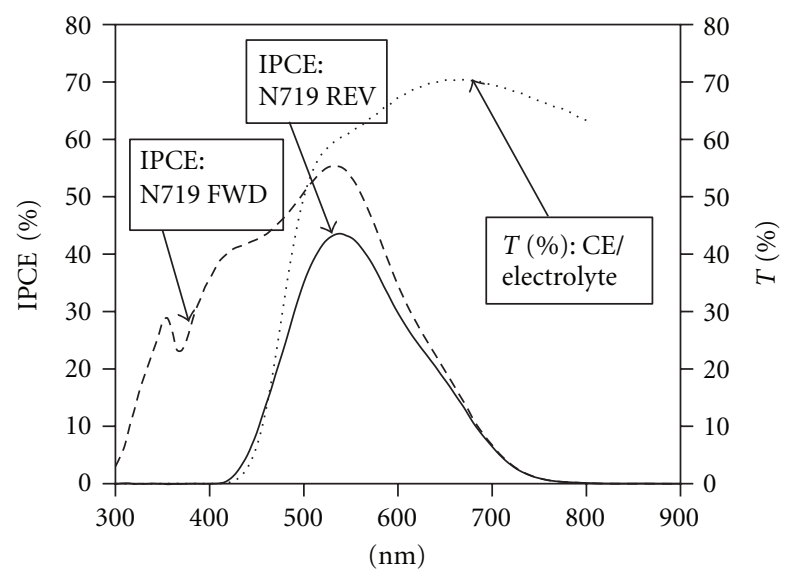

FIgure 7: The IPCE spectra of a cell made with N719 dye and measured in both forward (FWD) and reverse (REV) illumination. The UV-Vis $\% T$ curve of a model cell is also shown. The model cell consists of a platinised counter electrode (TCO glass), the electrolyte and ordinary soda-lime glass in place of the working electrode. The model cell simulates the filtering caused by the counter electrode and electrolyte when a DSC device is operated in reverse illumination.

under forward illumination, filtering does not significantly alter the shape of the spectra with the exception of the extreme filtering provided by $\lambda_{480}$. Table 4 summarises the mean properties of reverse illuminated devices with and without their filters. Once again it is arguably more helpful to compare efficiency losses caused by the filters to the PET $\lambda_{320}$ filter rather than the unfiltered cell and so Figure 9 shows a bar chart summarising the relative $\% \eta$ losses caused by filtering in reverse illuminated cells compared to the $\% \eta$ of cells filtered with $\lambda_{320}$.

Looking at Figure 9 it is clear that efficiency losses due to filtering at all levels in reverse illuminated cells are less severe than that seen in forward illuminated cells. Similarly to the forward illuminated cells, the dye with the narrowest 


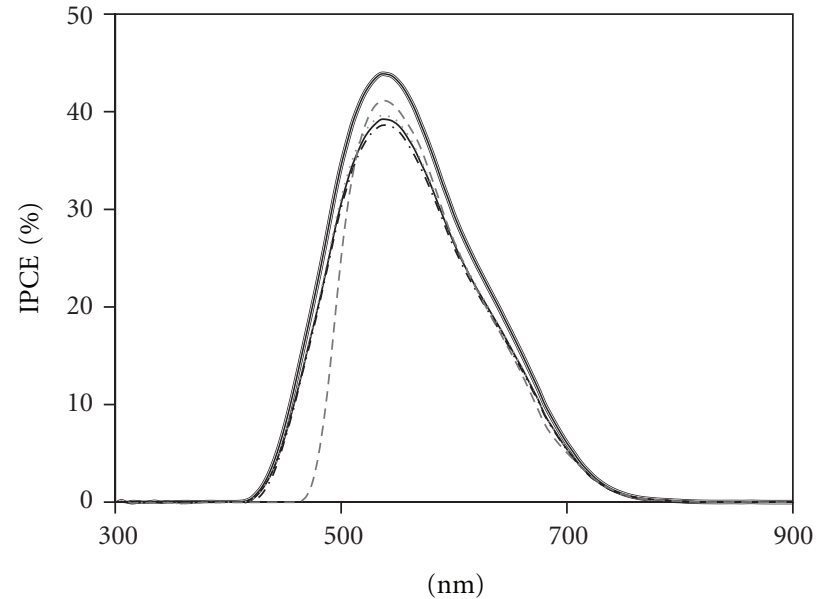

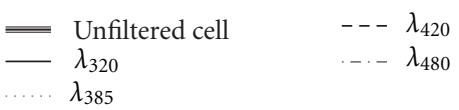

(a)
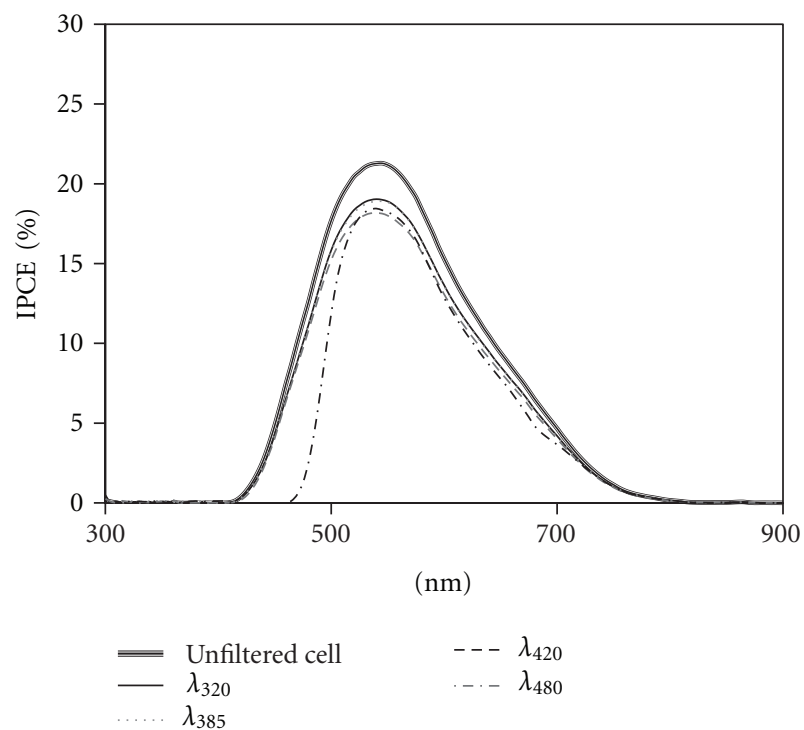

(b)

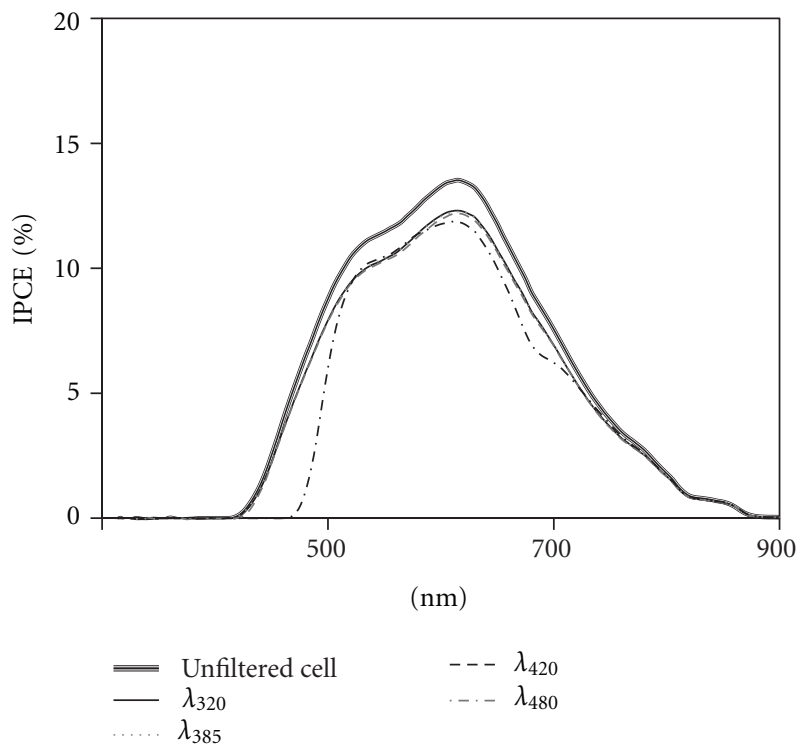

(c)

FIGURE 8: The effects of filtering upon the IPCEs of DSCs made with three different dyes, (a) N719, (b) Z907, and (c) N749, and measured under forward illumination.

action spectrum, Z907, suffers the greatest efficiency losses. It is interesting to note that in this case the relative efficiency losses are marginally greater in N749 cells than in N719 cells but this is probably due to the much lower overall $\% \eta$ and IPCE exhibited by the N749 cell in reverse illumination. There are also some negative values in Figure 9 indicating that there are some efficiency improvements in going from a $\lambda_{320}$ filter to a $\lambda_{385}$ filter and once again these are probably due to the antireflection properties of the PET/PU film.

For reverse illuminated cells, the antireflection properties of the $\lambda_{385}$ filter are more prominent and there is a $\% \eta$ increase in going from a $\lambda_{320}$ filter to a $\lambda_{385}$ filter in both N719 and N749 cells and neither an increase nor a decrease in
$\% \eta$ for Z907 cells. From the $\% \eta$ losses caused by the $\lambda_{420}$ filter, which is above what might be required to prevent direct band gap $\mathrm{TiO}_{2}$ (anatase) excitation, it could be estimated that relative $\% \eta$ losses caused by filtering in order to prevent $\mathrm{TiO}_{2}$ excitation should be around $2 \%$. In other words a DSC module upon a steel substrate of say $7.0 \%$ efficiency might be expected to show an efficiency of around $6.86 \%$ with filtering at that level. The only filter that causes an alteration to the shape of the reverse illuminated IPCE spectra is the $\lambda_{480}$ filter, and, in this case, the pattern exhibited by the forward illuminated cells is repeated in that N749 suffers the least relative loss in efficiency and Z907 suffers the greatest. 
TABLE 4: Summary of $I-V$ data for filtered and unfiltered, reverse illuminated cells.

\begin{tabular}{lccccc}
\hline Dye-filter & $V_{\mathrm{OC}}(\mathrm{V})$ & $J_{\mathrm{SC}}\left(\mathrm{mA} \mathrm{cm}^{-2}\right)$ & $P_{\max }(\mathrm{mW})$ & Fill factor & $\% \eta$ \\
\hline N719-unfiltered & $0.721( \pm 0.008)$ & $4.62( \pm 0.13)$ & $2.31( \pm 0.07)$ & $0.77( \pm 0.007)$ & $2.56( \pm 0.08)$ \\
N719- $\lambda_{320}$ & $0.707( \pm 0.010)$ & $4.12( \pm 0.10)$ & $2.03( \pm 0.06)$ & $0.77( \pm 0.005)$ & $2.25( \pm 0.07)$ \\
N719- $\lambda_{385}$ & $0.706( \pm 0.011)$ & $4.17( \pm 0.11)$ & $2.06( \pm 0.06)$ & $0.78( \pm 0.005)$ & $2.28( \pm 0.07)$ \\
N719- $\lambda_{420}$ & $0.702( \pm 0.010)$ & $4.07( \pm 0.10)$ & $1.99( \pm 0.06)$ & $0.77( \pm 0.006)$ & $2.20( \pm 0.07)$ \\
N719- $\lambda_{480}$ & $0.695( \pm 0.013)$ & $3.58( \pm 0.11)$ & $1.74( \pm 0.06)$ & $0.78( \pm 0.004)$ & $1.93( \pm 0.06)$ \\
\hline Dye-filter & $V_{\mathrm{OC}}(\mathrm{V})$ & $J_{\mathrm{SC}}\left(\mathrm{mA} \mathrm{cm}^{-2}\right)$ & $P_{\max }(\mathrm{mW})$ & Fill factor & $0.73( \pm 0.034)$ \\
\hline Z907-unfiltered & $0.66( \pm 0.004)$ & $2.04( \pm 0.20)$ & $0.88( \pm 0.12)$ & $0.73( \pm 0.14)$ \\
Z907- $\lambda_{320}$ & $0.649( \pm 0.005)$ & $1.79( \pm 0.18)$ & $0.75( \pm 0.10)$ & $0.72( \pm 0.034)$ & $0.83( \pm 0.11)$ \\
Z907- $\lambda_{385}$ & $0.647( \pm 0.004)$ & $1.79( \pm 0.17)$ & $0.75( \pm 0.09)$ & $0.71( \pm 0.034)$ & $0.83( \pm 0.10)$ \\
Z907- $\lambda_{420}$ & $0.644( \pm 0.002)$ & $1.74( \pm 0.15)$ & $0.72( \pm 0.08)$ & $0.71( \pm 0.036)$ & $0.80( \pm 0.09)$ \\
Z907- $\lambda_{480}$ & $0.641( \pm 0.005)$ & $1.55( \pm 0.13)$ & $0.64( \pm 0.07)$ & $0.71( \pm 0.035)$ & $0.71( \pm 0.08)$ \\
\hline Dye-filter & $V_{\mathrm{OC}}(\mathrm{V})$ & $J_{\mathrm{SC}}(\mathrm{mAcm}-2)$ & $P_{\max }(\mathrm{mW})$ & Fill factor & $\% \eta$ \\
\hline N749-unfiltered & $0.674( \pm 0.015)$ & $2.83( \pm 0.45)$ & $1.27( \pm 0.18)$ & $0.74( \pm 0.006)$ & $1.41( \pm 0.20)$ \\
N749- $\lambda_{320}$ & $0.657( \pm 0.015)$ & $2.54( \pm 0.39)$ & $1.08( \pm 0.21)$ & $0.72( \pm 0.048)$ & $1.24( \pm 0.17)$ \\
N749- $\lambda_{385}$ & $0.658( \pm 0.017)$ & $2.58( \pm 0.41)$ & $1.13( \pm 0.16)$ & $0.74( \pm 0.004)$ & $1.25( \pm 0.17)$ \\
N749- $\lambda_{420}$ & $0.654( \pm 0.016)$ & $2.52( \pm 0.41)$ & $1.10( \pm 0.15)$ & $0.74( \pm 0.003)$ & $1.21( \pm 0.17)$ \\
N749- $\lambda_{480}$ & $0.647( \pm 0.015)$ & $2.28( \pm 0.36)$ & $0.98( \pm 0.14)$ & $0.74( \pm 0.005)$ & $1.09( \pm 0.15)$ \\
\hline
\end{tabular}

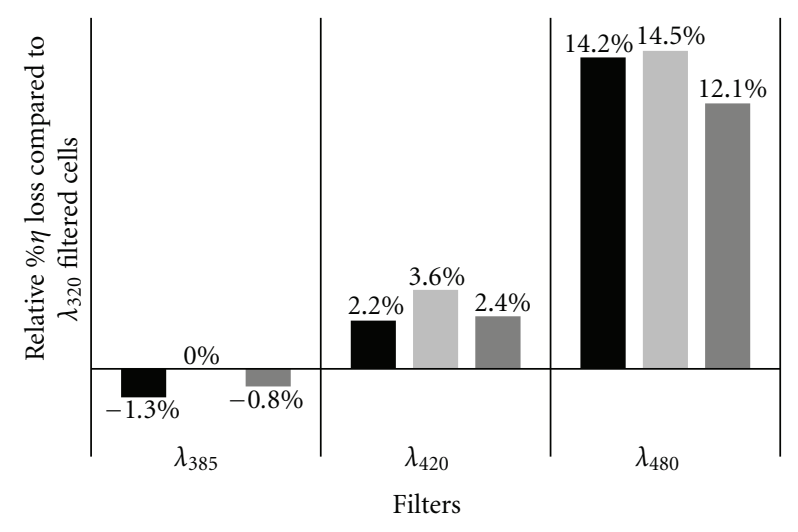

N719

Z907

N749

FIGURE 9: Efficiency losses in reverse illuminated cells caused by the filters shown and compared to cells filtered with the $\lambda_{320}$ filter.

Since the electrolyte, and counter electrode are such an effective UV filter, it might be questioned whether a UV filter is necessary in reverse illuminated cells at all, but it has been shown that cells exposed to UV irradiation from the counter electrode side still undergo photodegradation, albeit at a much slower rate, via the same mechanism as forward exposed cells [20].

\section{Conclusion}

Efficiency losses caused by UV filtering are presently inevitable with current technology and filtering is essential in order to ensure long-term stability of DSC devices. Nonetheless, those working toward the industrialisation of DSC technology should find the results of this work encouraging. A filter that has a $\% T$ of less than $1 \%$ below $390 \mathrm{~nm}$ should ensure stability by impeding direct band gap excitation of the $\mathrm{TiO}_{2}$ semiconductor. The $\lambda_{420}$ filter used in this study has a $\% T<1$ at below $405 \mathrm{~nm}$ and so perhaps provides more filtering than might be required. However, it can be estimated from the relative efficiency losses caused by the $\lambda_{420}$ filter that filtering to prevent $\mathrm{TiO}_{2}$ excitation should cause a drop in relative efficiencies of around 10\% for forward illuminated devices and around $2 \%$ for reverse illuminated devices.

This work also emphasises the well-recognised need to extend the absorption spectrum of dyes into the NIR region: as UV photons are blocked by the filter, more NIR photons need to be captured in order to compensate. This work also raises the issue of light filtering by the counterelectrode and the electrolyte in devices where reverse illumination is required. This is usually the case where the working electrode substrate is opaque, such as cells with metal-based photoelectrodes. The relative efficiency loss in a reverse illuminated cell can be up to $35 \%$ compared to the equivalent forward illuminated cell. If electrolytes could be developed where neither the components nor the redox mediator absorbed significant light from $300 \mathrm{~nm}$ to $1000 \mathrm{~nm}$, then this would increase the efficiency of devices that require reverse illumination considerably.

Finally, the antireflection properties of topsheet and encapsulation materials are an essential consideration for DSC module development. The antireflection mechanism of the $\lambda_{385}$ filter is fairly crude and simply arises as a result of the difference in the refractive indices of the PET substrate and the PU lacquer. More sophisticated antireflection technologies such as multiple layer polymer films and even biomimicry films produced by nanolithography could be utilised in order to increase light transmission and therefore cell performance and efficiency. 


\section{Acknowledgments}

The authors would like to acknowledge support from the Engineering Physical Science Research Council (EP/ E035205), the ERDF through the Low Carbon Research Institute, Tata Steel Europe, PV Accelerator, Shotton Works, Deeside, and SPECIFIC at the College of Engineering, Swansea University. They would also like to thank Dyesol, St. Asaph, UK for the use of their IPCE.

\section{References}

[1] A. Hinsch, J. M. Kroon, R. Kern et al., "Long-term stability of dye-sensitised solar cells," Progress in Photovoltaics, vol. 9, no. 6, pp. 425-438, 2001.

[2] P. M. Sommeling, M. Späth, H. J. P. Smit, N. J. Bakker, and J. M. Kroon, "Long-term stability testing of dye-sensitized solar cells," Journal of Photochemistry and Photobiology A, vol. 164, no. 1-3, pp. 137-144, 2004.

[3] M. Grätzel, "Solar energy conversion by dye-sensitized photovoltaic cells," Inorganic Chemistry, vol. 44 , no. 20 , pp. $6841-$ 6851, 2005.

[4] A. Barkschat, T. Moehl, B. MacHt, and H. Tributsch, "The function of $\mathrm{TiO}_{2}$ with respect to sensitizer stability in nanocrystalline dye solar cells," International Journal of Photoenergy, vol. 2008, Article ID 814951, 13 pages, 2008.

[5] N. Kato, K. Higuchi, H. Tanaka, J. Nakajima, T. Sano, and T. Toyoda, "Improvement in long-term stability of dye-sensitized solar cell for outdoor use," Solar Energy Materials and Solar Cells, vol. 95, no. 1, pp. 301-305, 2011.

[6] N. Kato, Y. Takeda, K. Higuchi et al., "Degradation analysis of dye-sensitized solar cell module after long-term stability test under outdoor working condition," Solar Energy Materials and Solar Cells, vol. 93, no. 6-7, pp. 893-897, 2009.

[7] H. Matsui, K. Okada, T. Kitamura, and N. Tanabe, "Thermal stability of dye-sensitized solar cells with current collecting grid," Solar Energy Materials and Solar Cells, vol. 93, no. 6-7, pp. 1110-1115, 2009.

[8] M. Toivola, J. Halme, L. Peltokorpi, and P. Lund, "Investigation of temperature and aging effects in nanostructured dye solar cells studied by electrochemical impedance spectroscopy," International Journal of Photoenergy, vol. 2009, Article ID 786429, 15 pages, 2009.

[9] R. Harikisun and H. Desilvestro, "Long-term stability of dye solar cells," Solar Energy, 2010.

[10] M. I. Asghar, K. Miettunen, J. Halme et al., "Review of stability for advanced dye solar cells," Energy and Environmental Science, vol. 3, no. 4, pp. 418-426, 2010.

[11] B. O'Regan and M. Grätzel, "A low-cost, high-efficiency solar cell based on dye-sensitized colloidal $\mathrm{TiO}_{2}$ films," Nature, vol. 353, no. 6346, pp. 737-740, 1991.

[12] H. G. Agrell, J. Lindgren, and A. Hagfeldt, "Degradation mechanisms in a dye-sensitized solar cell studied by UV-VIS and IR spectroscopy," Solar Energy, vol. 75, no. 2, pp. 169-180, 2003.

[13] H. Tanaka, A. Takeichi, K. Higuchi et al., "Long-term durability and degradation mechanism of dye-sensitized solar cells sensitized with indoline dyes," Solar Energy Materials and Solar Cells, vol. 93, no. 6-7, pp. 1143-1148, 2009.

[14] P. T. Nguyen, A. Rand, E. Morten Skou, and T. Lund, "Dye stability and performances of dye-sensitized solar cells with different nitrogen additives at elevated temperaturesCan sterically hindered pyridines prevent dye degradation?" Solar
Energy Materials and Solar Cells, vol. 94, no. 10, pp. 1582$1590,2010$.

[15] M. Grätzel, "Photovoltaic performance and long-term stability of dye-sensitized meosocopic solar cells," Comptes Rendus Chimie, vol. 9, no. 5-6, pp. 578-583, 2006.

[16] B. Macht, M. Turrión, A. Barkschat, P. Salvador, K. Ellmer, and H. Tributsch, "Patterns of efficiency and degradation in dye sensitization solar cells measured with imaging techniques," Solar Energy Materials and Solar Cells, vol. 73, no. 2, pp. 163173, 2002.

[17] A. Hauch and A. Georg, "Diffusion in the electrolyte and charge-transfer reaction at the platinum electrode in dyesensitized solar cells," Electrochimica Acta, vol. 46, no. 22, pp. 3457-3466, 2001.

[18] H. Pettersson and T. Gruszecki, "Long-term stability of low-power dye-sensitised solar cells prepared by industrial methods," Solar Energy Materials and Solar Cells, vol. 70, no. 2, pp. 203-212, 2001.

[19] K. Tennakone, G. R. R. A. Kumara, I. R. M. Kottegoda, K. G. U. Wijayantha, and V. P. S. Perera, "A solid-state photovoltaic cell sensitized with a ruthenium bipyridyl complex," Journal of Physics D, vol. 31, no. 12, pp. 1492-1496, 1998.

[20] M. Carnie, D. Bryant, T. Watson, and D. Worsley, "Photocatalytic oxidation of triiodide in UVA-exposed dye-sensitized solar cells," International Journal of Photoenergy, vol. 2012, Article ID 524590, 8 pages, 2012.

[21] P. Wang, S. M. Zakeeruddin, P. Comte, R. Charvet, R. Humphry-Baker, and M. Grätzel, "Enhance the performance of dye-sensitized solar cells by co-grafting amphiphilic sensitizer and hexadecylmalonic acid on $\mathrm{TiO}_{2}$ nanocrystals," Journal of Physical Chemistry B, vol. 107, no. 51, pp. 1433614341, 2003.

[22] P. Wang, S. M. Zakeeruddin, R. Humphry-Baker, and M. Grätzel, "A binary ionic liquid electrolyte to achieve $\geq 7 \%$ power conversion efficiencies in dye-sensitized solar cells," Chemistry of Materials, vol. 16, no. 14, pp. 2694-2696, 2004.

[23] A. W. Czanderna, C. N. Ramachandra Rao, and J. M. Honig, "The anatase-rutile transition: part 1. Kinetics of the transformation of pure anatase," Transactions of the Faraday Society, vol. 54, pp. 1069-1073, 1958.

[24] M. A. Fox and M. T. Dulay, "Heterogeneous photocatalysis," Chemical Reviews, vol. 93, no. 1, pp. 341-357, 1993.

[25] M. K. Nazeeruddin, P. Péchy, T. Renouard et al., "Engineering of efficient panchromatic sensitizers for nanocrystalline $\mathrm{TiO}_{2}$ based solar cells," Journal of the American Chemical Society, vol. 123, no. 8, pp. 1613-1624, 2001.

[26] M. J. Carnie, T. M. Watson, D. T. J. Bryant, and D. A. Worsley, "Electrochemical characterization of the UVphotodegradation of dye-sensitized solar sells and usage in the assessment of UV-protection measures," ECS Transactions, vol. 41, no. 4, pp. 93-102, 2011.

[27] A. Hagfeldt and L. Peter, "Characterisation and modeling of dye-sensitised solar cells: a toolbox approach," in DyeSensitized Solar Cells, K. Kalyanasundaram, Ed., EPFL Press, Lausanne, Switzerland, 2010.

[28] A. Yella, H.-W. Lee, H. N. Tsao et al., "Porphyrin-sensitized solar cells with cobalt (II/III)-based redox electrolyte exceed 12 percent efficiency," Science, vol. 334, no. 6056, pp. 629-634, 2011. 


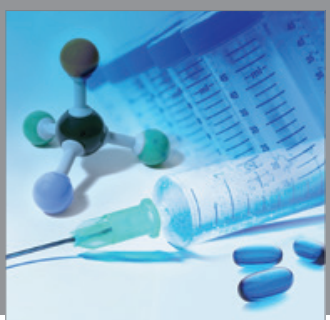

International Journal of

Medicinal Chemistry

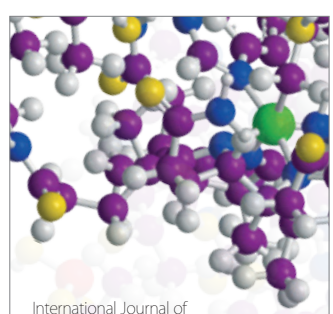

Carbohydrate Chemistry



The Scientific World Journal
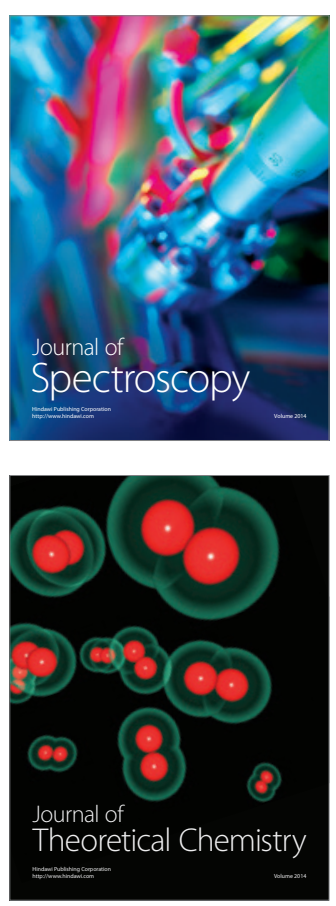
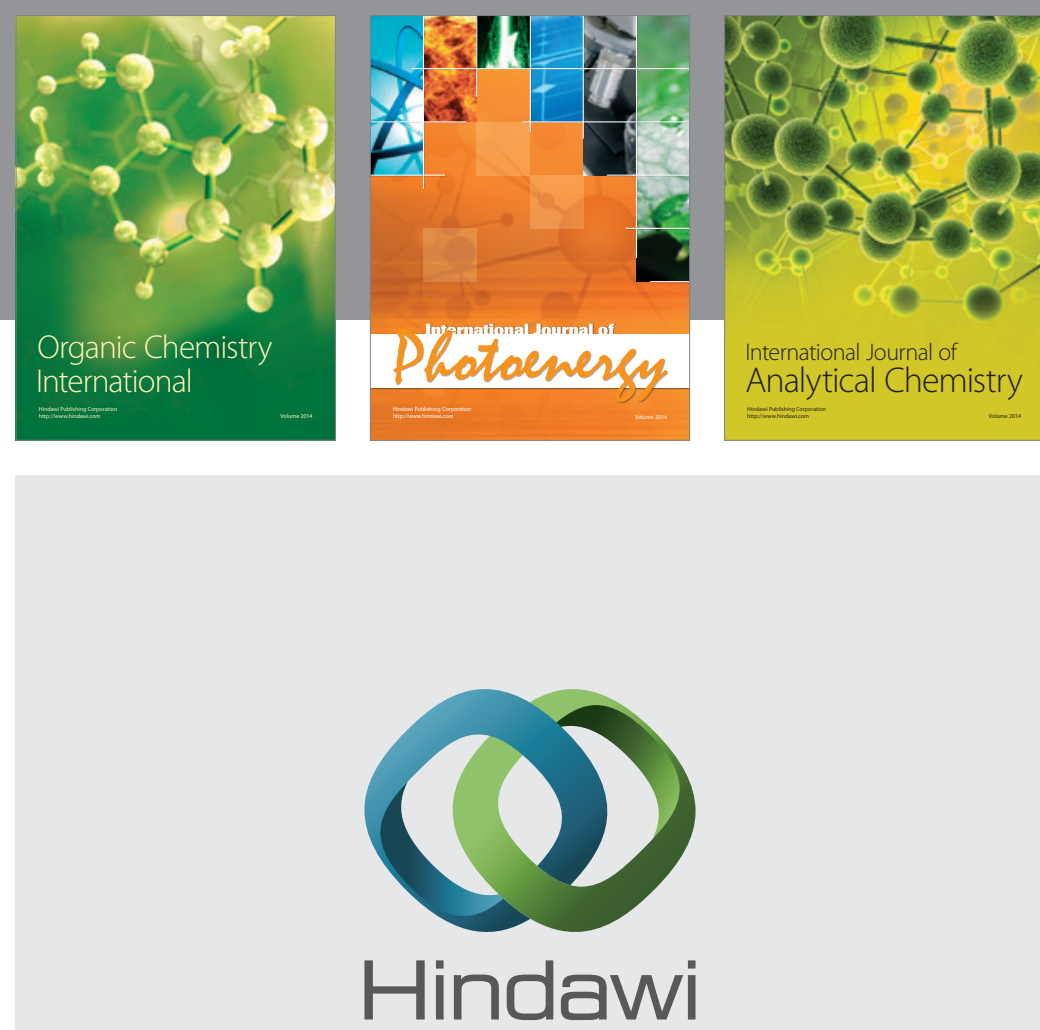

Submit your manuscripts at

http://www.hindawi.com
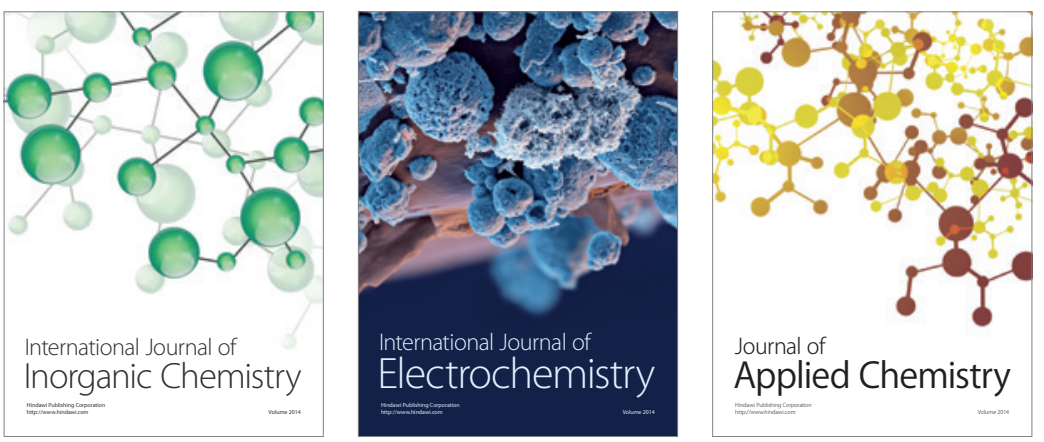

Journal of

Applied Chemistry
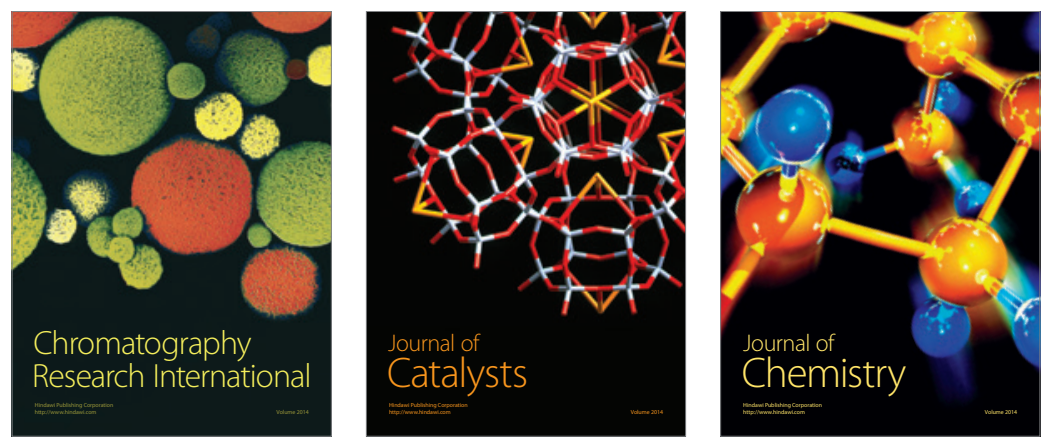
